\title{
Cenplesto
}

\section{Repercussão da Teoria do Conhecimento Tácito de Michael Polanyi: anais da KM Brasil 2002-2018}

\author{
Josemar Elias da Silva Junior \\ Doutorando; Universidade Federal da Paraíba, João Pessoa, PB, Brasil; \\ josemar.elias90@gmail.com \\ Joana Coeli Ribeiro Garcia \\ Doutora; Universidade Federal da Paraíba, João Pessoa, PB, Brasil; \\ nacoeli@gmail.com
}

Resumo: As discussões acerca da epistemologia do conhecimento são bastante antigas e percorrem áreas das Ciências da Saúde até as Sociais Aplicadas. Nela temos uma figura importante: Michael Polanyi, propondo uma perspectiva harmoniosa para a criação do conhecimento, rompendo o ideal de objetividade absoluto herdado da Revolução Científica do século XVIII. A pesquisa qualiquanti utiliza como coleta de dados os documentos publicados nos anais do Congresso Nacional de Gestão do Conhecimento - KM BRASIL (2002-2018) que citam o conceito de Polanyi sobre conhecimento tácito com o objetivo de identificar como suas ideias estão referidas, os sentidos usados e seu desenvolvimento. Nessa direção, a partir do KM BRASIL evidenciamos autores, filiações, data de publicação, incluindo possibilidades de interpretar as ideias de Polanyi. Constatamos que a teoria é abordada conceitualmente no contexto brasileiro, correspondendo a pouco mais de $5 \%$ do total de trabalhos publicados nos 13 anos de evento. Embora a temática da gestão do conhecimento ocupe o centro das discussões do evento, somente tal percentual cita os estudos de Michael Polanyi. Com efeito, os autores selecionados afirmam ancorar-se nos preceitos de Polanyi para explicar a epistemologia do conhecimento e sua categorização. Posteriormente os autores inserem a noção de gestão e a distinção entre o tácito e o explicíto a partir de Nonaka e Takeuchi. Apreendemos que o introito para as discussões sobre gestão, criação, transferência ou armazenamento de conhecimento partiram sempre da epistemologia polanyiana embora nem sempre de forma fidedigna.

Palavras-chave: Conhecimento tácito. Michael Polanyi. KM Brasil.

\section{Introdução}

No contexto empresarial, o conhecimento é matéria-prima para capacitar pessoas, articular as tomadas de decisões, propor diversidade de práticas laborais e potencializar resultados das empresas (ALBAGLI, 2005). Razão pela qual "os reflexos da sociedade contemporânea despertam a necessidade de 
constantes adequações e inovações nos produtos e serviços oferecidos pelas organizações modernas" (SANTA ANNA, 2015, p.77). De modo geral, são empresas que se veem pressionadas a criar e desenvolver estratégias que promovam a eficiência e adequação de produtos e/ou serviços oferecidos ao mercado, exigindo de seus colaboradores que permaneçam com conhecimento adequado a cada situação, que seja explicitado, comunicado e socializado, e que possibilitem que as estratégias planejadas se transformem em práticas e ações consequentes.

Na contemporaneidade, surge uma classificação que distingue dois tipos de conhecimento: o tácito e o explícito. No primeiro caso, trata-se do conhecimento presente no campo das ideias, portanto pessoal e difícil de externar em códigos, como citado por Polanyi (1966) - o tácito. Em relação ao segundo, configura-se o tácito socializado e, muitas vezes, registrado em um suporte, portanto, na condição de ser - o explicitado.

Quando Michael Polanyi (1966) apresenta a assertiva, nós conhecemos mais do que conseguimos falar, neste limiar situa o conhecimento enquadrado como tácito, aquele que "[...] nós possuímos dentro de nós mesmos, fruto do aprendizado e da experiência que desenvolvemos ao longo de nossa vida" (CRUZ, 2002, p. 262) e na maioria das vezes nem nos damos conta de que o possuímos. A teoria polanyana advém da averiguação da importância decisiva deste conhecimento específico (CARDOSO; CARDOSO, 2007).

No tocante ao conhecimento explícito, este pode ser compreendido como aquele que reside fora do campo cognitivo do ser, ou seja, "o conhecimento documentado e contido em informações não estruturadas" (SANTA'ANNA, 2015 , p. 86). De certo modo, este conhecimento passou por um processo de socialização e incorporação por parte dos indivíduos, e em razão disto, encontrase materializado em um suporte, ou somos conscientes de sua existência, seja “[...] aquele que externamos formalmente ou não”. (CRUZ, 2002, p. 262).

Sob justificativa científica, cumpre trazer à baila um dos principais precursores da epistemologia do conhecimento, responsável por impetrar a ideia do que considera conhecimento. No caso, Michael Polanyi, nascido na Hungria em 1891, formado em medicina, estudioso da físico-química e outras áreas. 
Química, física, epistemologia, economia, lei de patentes, teoria social e política, estética e teologia (SCOTT; MOLESKI, 2005) são algumas das suas preocupações. Sobretudo, permanece citado por estudiosos até os dias atuais em virtude das ideias e dos escritos sobre conhecimento tácito. Razão que leva a investigar: como se apresentam as temáticas que avocam, apresentam, discutem e referenciam Michael Polanyi e as perspectivas teóricas do conhecimento tácito em textos publicados nos anais do evento KM Brasil.

As motivações pessoais para a propositura do trabalho residem no fato de Michael Polanyi ser o autor da teoria do conhecimento objeto de estudo dos autores do artigo. Neste texto, eles dedicam-se a realizar explorações e reflexões sobre o uso da temática, para investigar as discussões apresentadas por estudiosos brasileiros da área da administração.

Por outro lado, o estudo proposto por Grant (2007) em panorama internacional investiga a consistência/coerência do uso dos conceitos de Polanyi, mediante análise de três periódicos distintos. Literatura atual e estimulante, identifica como o pensamento do estudioso tem sido compreendido nestas diversas formas de apreensão. A seguir, apresentamos o percurso metodológico, o pensamento de Polanyi, e posteriormente a análise dos resultados.

\section{Metodologia}

O artigo é de natureza quali-quantitativa, uma vez que adota como método de coleta de dados a pesquisa documental, lançando mão das publicações científicas: relatórios técnicos, posters, comunicação oral e outros publicados no evento científico KM BRASIL no período de 2002 a 2018, correspondendo às edições do evento, disponíveis eletronicamente até o momento da pesquisa, janeiro de 2020, época em que realizamos a coleta dos dados.

Justificamos o estudo dos anais das edições do KM BRASIL (20022018) por se constituir o evento que nacionalmente trabalha a temática, portanto o divulgador de discussões acerca de conhecimento, oferecendo subsídios para evidenciar autores que a partir de Michael Polanyi estruturam seus trabalhos. De outra parte, estamos nos familiarizando para investir em estudos mais aprofundados sobre a teoria deste autor. Ainda no tocante a escolha dos anais, 
ocorre por ser terreno fértil para a adoção da teoria do conhecimento. É organizado pela Sociedade Brasileira de Gestão do Conhecimento (SBGC) que na América Latina congrega profissionais, consultores, pesquisadores e professores dos setores privados, do governo e do terceiro setor.

Portanto, evidenciamos os dados quantificáveis sobre as produções que citam Polanyi (1966), da mesma maneira de natureza qualitativa, tendo em vista que as perspectivas temáticas estão analisadas, como proposto no Quadro 1.

Quadro 1 - Esquema metodológico

\begin{tabular}{|c|c|c|}
\hline Natureza da pesquisa & Variável & Operacionalização \\
\hline \multirow{4}{*}{ Qualitativa } & Discussão teórica & $\begin{array}{c}\text { Revisão livros, artigos de } \\
\text { periódicos e eventos }\end{array}$ \\
\cline { 2 - 3 } & Seleção do corpus & $\begin{array}{c}\text { Consulta e análise documentos } \\
\text { publicados }\end{array}$ \\
\hline \multirow{4}{*}{ Quantitativa } & Artigos do KM Brasil & $\begin{array}{c}\text { Uso da lista de referências as obras } \\
\text { de Michael Polanyi }\end{array}$ \\
\cline { 2 - 2 } & Autores de artigos & $\begin{array}{c}\text { Identificação de artigos, autores e } \\
\text { instituições e referências a } \\
\text { Michael Polanyi }\end{array}$ \\
\cline { 2 - 2 } & $\begin{array}{c}\text { Instituições de pertencimento } \\
\text { dos autores }\end{array}$ & Referências a obras de Michael \\
\cline { 2 - 2 } & Polanyi & \\
\hline
\end{tabular}

Fonte: Elaborado pelos autores.

No tocante à técnica da revisão sistemática, segundo Sampaio e Mancini (2007, p. 84) se traduz em estudo "como forma de pesquisa que utiliza como fonte de dados a literatura sobre determinado tema”. Nesta direção, a utilização da técnica tem o intuito de sintetizar o conhecimento produzido em um determinado assunto e separar as produções científicas relevantes ou não dentro da propositura de pesquisa. A revisão sistemática revela-se em "[...] uma forma de se apropriar das melhores evidências externas, contribuindo para a tomada de decisão baseada em evidência" (PEREIRA; BACHION, 2006, p. 492).

Para realizar o levantamento dos trabalhos que mencionam Polanyi e proceder com a revisão sistemática, preliminarmente partimos da verificação da lista de referências com o foco em identificar se uma das obras do autor foi elencada. Em seguida, para a identificação da citação no texto com vistas a averiguar sob que circunstâncias as ideias foram expostas. Por fim, para o 
levantamento de palavras-chave e outros metadados para caracterizar autores, filiações, títulos dos trabalhos que utilizaram Michael Polanyi em suas produções, seja para estimular a criação como ele a idealizou, seja para gerenciar contrariando-o. São dados quantitativos das produções vinculadas às ideias de Polanyi discutidas na seção análise dos resultados desse artigo.

Por intermédio do KM BRASIL, evidenciamos pelo viés quantitativo, autores, respectivas filiações e data de publicação tabulados no Quadro 2. Para com isso, verificarmos pelo viés qualitativo as possibilidades de interpretação de suas ideias. Como fundamentação, tratamos na seção seguinte da teoria do conhecimento tácito proposta por Polanyi (1966) para subsidiar o estudo.

\section{Michael Polanyi e a inscrição teórica do Conhecimento Tácito}

Nesse artigo, é importante trazer apontamentos quanto à teoria do conhecimento de Michael Polanyi, evidenciando aspectos históricos do autor, da criação dessa teoria e das bases científicas para sua formulação. Além disso, trazemos de forma sucinta um desdobramento sobre o diagrama "from-to" que o autor utiliza para explicar o processo de criação de conhecimento enquanto ação de querer conhecer.

O século XX trouxe consigo inúmeras mudanças, em especial a difusão de tecnologias, que envolvem os processos de comunicação e informação, uma vez que viabilizam a transmissão, o processamento e o armazenamento de grande número de dados e informações em alta velocidade, baixo valor financeiro e diversidade de aplicações (ALBAGLI, 2005).

O conhecimento passa a ser peça-chave para desenvolver ações, bem como proporcionar capacitação para o manuseio destas tecnologias. Registramse que ações de "[...] conhecimento e voltadas para o desenvolvimento de produtos e processos estão se tornando as principais funções internas das empresas e aquelas com maior potencial de obtenção de vantagem competitiva" (TEIXEIRA, 2018, p. 3).

A partir das discussões em torno das possibilidades de socialização do conhecimento, deparamos com debates acerca da diferenciação entre tácito e explícito, encontrando Michael Polanyi como principal idealizador da teoria do 
conhecimento, defendida desde o século XIX. Estudioso, marcado pela originalidade e fertilidade na formulação de ideias, disseminou escritos que “perpassam a química do líquido hidrocefálico, estudando a físico-química do cérebro, e, em suas incursões pela filosofia, ele se volta às questões relacionadas ao conhecimento" (GARCIA; SILVA, 2015, p.7).

Dentre as obras de maior referenciação de Michael Polanyi estão: em 1946, Science, faith and society; em 1958, Personal knowledge; em 1966, Towards a post-critical philosophy e The tacit dimension. Pioneiro nas discussões acerca da existência de uma dimensão tácita no conhecimento, proporcionou avanços no século XX para discussões sobre conhecimento e gestão, colocando em evidência a importância do conhecimento tácito. Este último, sendo o que não identificamos, mas sabemos que possuímos.

Grant (2007) pesquisa, em 2006, três periódicos de gestão do conhecimento: Journal of Intellectual Capital, Journal of Knowledge Management e Knowledge and Process Management e seleciona 52 artigos que mencionam Michael Polanyi como referência bibliográfica. São obras usadas para compreender pontos deficitários da "Primeira Geração da Gestão do Conhecimento"1.

Importa mencionar que Grant (2007) procede o estudo instigado pelo desejo de compreender o engajamento dos estudiosos quanto à apropriação das ideias de Polanyi, na perspectiva de entender as referências ao autor como contribuição fundamental e inicial para o conceito de conhecimento tácito ou como referência específica a alguma variante de única citação: "nós sabemos mais do que podemos dizer" (POLANYI, 1966). E, ainda, identificar se os autores realmente leram a obra, e se a citação, ao ser usada, apoia o argumento teórico dos autores. 
Figura 1 - Diagrama from-to de Polanyi

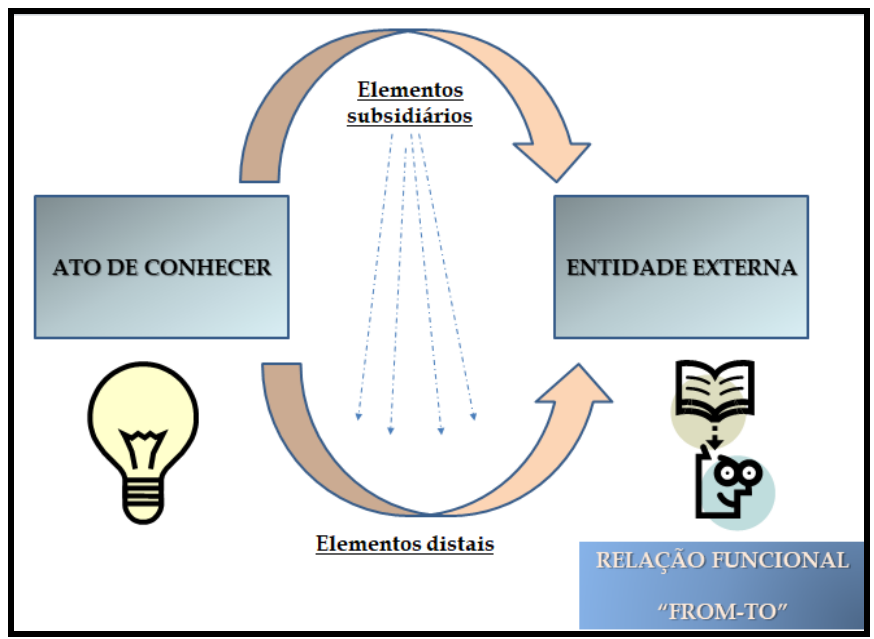

Fonte: Adaptado de Polanyi (1966).

Nessa direção, Michael Polanyi compreende a estrutura do conhecimento tendo no tácito sua dimensão mais intrínseca, observando-se no processo de sua apreensão uma relação funcional entre dois componentes: elementos subsidiários (predisposições já existentes no campo cognitivo do sujeito e não perceptíveis pelo cérebro) e elementos distais (o que se quer perceber).

Ao postular que o conhecimento não é privado, mas sim social. Polanyi pretende enfatizar que este é socialmente construído e se funde com experiência pessoal da realidade ou, dito de outra forma, só é possível adquirir conhecimento quando o indivíduo se encontra em contacto com situações que propiciam experiências, que são sempre assimiladas através dos conceitos que o indivíduo dispõe que são, por natureza, tácitos - herdados previamente de uma mesma linguagem. (CARDOSO; CARDOSO, 2007).

Cumpre pontuar que Polanyi fundamenta sua teoria na Psicologia da Gestalt (psicologia da forma), afirmando que não podemos compreender o todo a partir de suas partes, tendo em vista que o todo é maior que a mera soma das partes. Desta forma, o conhecimento seria a capacidade de ação, como demonstrado.

O processo de busca do conhecimento constitui um ato/atividade que revela o interesse em compreender ou descobrir uma realidade - o elemento distal -, o sujeito é imbuído de pistas ou fragmentos - elementos subsidiários adquiridos a partir das experiências rotineiras - incidência da teoria de Gestalt - 
na qual por meio da articulação destes últimos (subsidiários) é possível partir para o primeiro (distal). Neste sentido, o tacit knowledge pode ser compreendido como aquele conhecimento que envolve habilidades, experiências e intuição (NONAKA, 1994).

Garcia e Silva (2015, p. 9) assinalam que os que defendem o conhecimento tácito “[...] dizem que ele é o único produto do pensamento intelectual por natureza e, ao defender o conhecimento explícito, afirmam que os seres humanos chegam a ele como consequência de vivenciar o lado qualitativo da experiência". Em atenção a esta estrutura criada por Polanyi (1966, p.8), "todos os pensamentos contêm componentes de que estamos subsidiariamente cientes do seu conteúdo focal, e que todo o pensamento habita nos seus subsidiários, como se fizessem parte do nosso corpo". Depreendemos, então, que o conhecimento tácito exprime, muitas vezes, aspectos e atitudes que não reconhecemos em nós, despertados pelos elementos distais.

Embora haja discussão acerca da possibilidade de haver um gerenciamento do conhecimento, em artigo acerca das contribuições polanyianas sobre a repercussão da existência ou não de uma gestão do conhecimento humano, aponta que

[...] elementos explícitos são objetivos, racionais e criados no aqui e ali, enquanto os elementos tácitos são experienciais, subjetivos e criados no aqui e agora. Assim sendo, continuamos reforçando que há dificuldades empíricas e teóricas para gerenciar conhecimento, defendendo, a criação e a socialização de conhecimento ao invés da gestão. (GARCIA; SILVA, 2015, p. 13)

Portanto, para Garcia e Silva (2015), o conhecimento pode ser exortado para ser compartilhado e criado, nunca gerenciado. Posto isso, Schartinger, Maia e Viola (2002), em uma pesquisa para verificar as interações entre indústrias e instituições de pesquisa na Áustria, compreenderam que o conhecimento tácito é transferido por meio de contato pessoal, mencionando técnicas que viabilizam tal processo: interaction, creation, generation, dissemination, diffusion, transfer, sharing, flow e spillovers ${ }^{2}$, chamando atenção para os canais de transferência que variam de acordo com a intensidade das relações. 


\section{Apresentação e discussão dos resultados}

Do total de 589 trabalhos científicos publicados e disponibilizados nos anais do KM BRASIL, dentre relatórios técnicos, posters, comunicação oral e outros, selecionamos, utilizando os termos Polanyi e Conhecimento tácito, 30 trabalhos que mencionam o autor do termo estudado, seja de forma direta, indireta ou por meio de outros autores.

Nos anos 2005 e 2009, não identificamos menção ao pesquisado, enquanto nos anos 2006, 2013, 2015 e 2017 o evento não se realizou, razão pela qual não há produção referente a esse período.

Quadro 2 - Dados levantados a partir de artigos que citam Michael Polanyi

\begin{tabular}{|c|c|c|c|}
\hline ATOR(ES) & FILIAÇÃO & TÍTULO DO TRABALHO & ANO \\
\hline Julia Strauch & EMBRAPA & \multirow{3}{*}{$\begin{array}{c}\text { Epistheme: ambiente } \\
\text { computacional de apoio à } \\
\text { gerência do conhecimento } \\
\text { científico }\end{array}$} & \multirow{6}{*}{2002} \\
\hline Jano M. Souza & UFRJ & & \\
\hline Jonice Oliveira & UFRJ & & \\
\hline Alsones Balestrin & UVRS & \multirow{3}{*}{$\begin{array}{l}\text { Geração de conhecimento e } \\
\text { inteligência estratégica no } \\
\text { universo das redes } \\
\text { interorganizacionais }\end{array}$} & \\
\hline Carolina Weyh & UVRS & & \\
\hline Gilberto A. Faggion & UVRS & & \\
\hline Renato Rocha Souza & UFMG & \multirow{2}{*}{$\begin{array}{l}\text { A construção do conceito de } \\
\text { gestão do conhecimento: } \\
\text { práticas organizacionais, } \\
\text { garantias literárias e o } \\
\text { fenômeno social }\end{array}$} & \multirow{8}{*}{2003} \\
\hline $\begin{array}{c}\text { Rivadávia Correa D. de } \\
\text { Alvarenga Neto }\end{array}$ & UFMG & & \\
\hline Luís C. Freire & FTCS- BA & $\begin{array}{c}\text { Comunidades de } \\
\text { aprendizagem: uma } \\
\text { abordagem integrada para a } \\
\text { gestão do conhecimento }\end{array}$ & \\
\hline Jairo G. Queiroz & $\begin{array}{c}\text { Operador } \\
\text { Nacional do } \\
\text { Sistema Elétrico }\end{array}$ & \multirow{2}{*}{ Criando o futuro: Sigop } & \\
\hline Marcio P. Silvado & $\begin{array}{c}\text { Operador } \\
\text { Nacional do } \\
\text { Sistema Elétrico } \\
\end{array}$ & & \\
\hline Cristine L. P. Griffo & UFES & \multirow{2}{*}{$\begin{array}{l}\text { Gestão de conhecimento: } \\
\text { uso de ontologia nas } \\
\text { tomadas de decisão }\end{array}$} & \\
\hline Davidson Cury & UFES & & \\
\hline Carlo Borsoi Moura & IPTSP & $\begin{array}{c}\text { Metodologia de mapeamento } \\
\text { de informações corporativas, } \\
\text { utilizando ontologias }\end{array}$ & \\
\hline
\end{tabular}




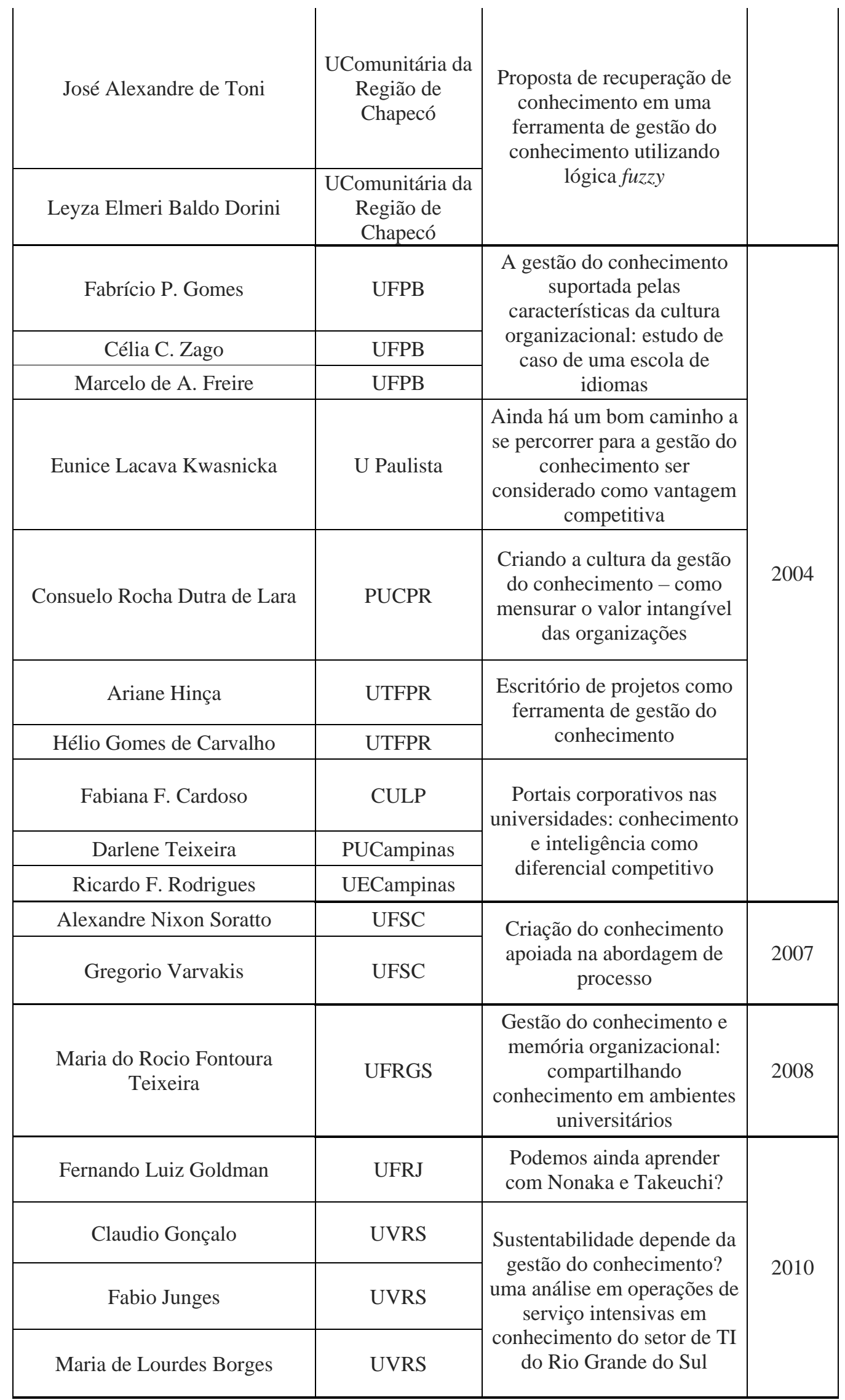




\begin{tabular}{|c|c|c|c|}
\hline Bárbara N. Barbosa Ritzmann & UFPR & \begin{tabular}{|} 
Análise bibliométrica sobre \\
os autores basilares \\
utilizados nas obras de \\
Ikujiro Nonaka: recorte de \\
artigos publicados de $1998-$ \\
2009
\end{tabular} & \multirow[t]{3}{*}{2011} \\
\hline Edelvino Razzollini Filho & UTFPR & \multirow{2}{*}{$\begin{array}{c}\text { Informação para criar } \\
\text { conhecimento em } \\
\text { organizações } \\
\text { autogestionárias - um estudo } \\
\text { de caso. } \\
\end{array}$} & \\
\hline Lourença Santiago Ribeiro & UTFPR & & \\
\hline Alexildo Vaz & $\mathrm{AGC}$ & $\begin{array}{l}\text { Quais os mais influentes } \\
\text { teóricos de gestão do } \\
\text { conhecimento para os seus } \\
\text { praticantes }\end{array}$ & 2011 \\
\hline Fernando Spanhol & UFSC & \multirow{2}{*}{$\begin{array}{c}\text { Epistemologia do } \\
\text { conhecimento: estado da } \\
\text { arte do conhecimento } \\
\text { organizacional } \\
\end{array}$} & \multirow{6}{*}{2012} \\
\hline Patricia de Sá Freire & UFSC & & \\
\hline Patrícia Fernanda Dorow & IFSC & \multirow{4}{*}{$\begin{array}{l}\text { História social do } \\
\text { conhecimento }\end{array}$} & \\
\hline João Artur de Souza & UFSC & & \\
\hline Juliana Augusto Clementi & UFSC & & \\
\hline Maurílio Tiago Brüning Schmitt & UFSC & & \\
\hline Carmen Lucia Fossari & UFSC & \multirow{5}{*}{$\begin{array}{l}\text { A utilização das ferramentas } \\
\text { de gestão do conhecimento } \\
\text { em uma empresa intensiva } \\
\text { de conhecimento - estudo de } \\
\text { caso do IBGE }\end{array}$} & \multirow{8}{*}{2014} \\
\hline Deizi Paula Giusti Consoni & UFSC & & \\
\hline Édis Mafra Lapolli & UFSC & & \\
\hline Ivana Fossari & UFSC & & \\
\hline Roberto Kern Gomes & UFSC & & \\
\hline Faimara R. Strauhs & UTFP & \multirow{3}{*}{\begin{tabular}{|c|} 
Teoria e prática das \\
condições habilitadoras do \\
ba na criação de \\
conhecimento
\end{tabular}} & \\
\hline Carlos M. Murasse & UTFP & & \\
\hline Priscila T.A. Moreira & UTFP & & \\
\hline Rosana Moreira & - & \multirow{3}{*}{$\begin{array}{l}\text { Ativos intangíveis, capital } \\
\text { intelectual e humano } \\
\text { relacionado à GC (AICI): A } \\
\text { prática da Gestão do } \\
\text { Conhecimento }\end{array}$} & \multirow{11}{*}{2016} \\
\hline $\begin{array}{c}\text { Alessandra dos Santos Libretti } \\
\text { Dias }\end{array}$ & PUCSP & & \\
\hline Neusa Maria Bastos & PUCSP & & \\
\hline Frederico Cesar Mafra Pereira & FPLeopoldo & \multirow{2}{*}{$\begin{array}{c}\text { Criação do conhecimento } \\
\text { baseada nos capacitadores de } \\
\text { Von Krogh, Nonaka e Ichijo: } \\
\text { estudo de caso na Granja DF } \\
\text { Pork, em Faria Lemos (MG) }\end{array}$} & \\
\hline Elisângela Freitas da Silva & UEMG & & \\
\hline Fernando B. Montenegro & ISTELA & \multirow{5}{*}{$\begin{array}{l}\text { Expert profiling: um modelo } \\
\text { para extração automática de } \\
\text { perfil de especialista para } \\
\text { apoio à expertise location e à } \\
\text { gestão do conhecimento }\end{array}$} & \\
\hline Paulo M. Selig & ISTELA & & \\
\hline Denilson Sell & UFSC & & \\
\hline José Leomar Todesco & UFSC & & \\
\hline Rudger N. Taxweiler & UFSC & & \\
\hline Fabricio Ziviani & FUMEC & Gestão do conhecimento e & \\
\hline
\end{tabular}




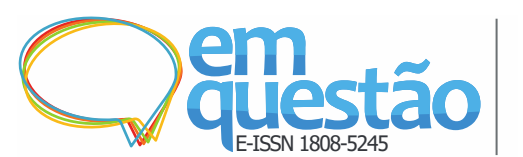

Repercutindo a teoria do conhecimento tácito de

Michael Polanyi nos anais da Km Brasil 2002 - 2018

Josemar Elias da Silva Junior e Joana Coeli Ribeiro Garcia

\begin{tabular}{|c|c|c|c|}
\hline Jorge Tadeu Ramos Neves & FUMEC & \multirow{4}{*}{$\begin{array}{l}\text { desempenho organizacional: } \\
\text { integração dinâmica entre } \\
\text { competências e recursos }\end{array}$} & \\
\hline $\begin{array}{l}\text { Jurema Suely de Araújo Nery } \\
\text { Ribeiro } \\
\end{array}$ & FUMEC & & \\
\hline Marco A. C. Soares & FUMEC & & \\
\hline Paulo H. A. Jurza & FUMEC & & \\
\hline Américo da Costa Ramos Filho & UFF & \multirow{2}{*}{$\begin{array}{l}\text { Gestão do conhecimento } \\
\text { pessoal e coaching no } \\
\text { contexto acadêmico: } \\
\text { possibilidades de } \\
\text { contribuição para o } \\
\text { desenvolvimento de alunos } \\
\text { de graduação }\end{array}$} & \\
\hline Leonardo Fernandes Souto & UFF & & \\
\hline Daniele C. Dantas & UFRJ & \multirow{4}{*}{$\begin{array}{c}\text { O uso do aplicativo } \\
\text { whatsapp nas práticas de } \\
\text { gestão do conhecimento: o } \\
\text { caso de uma comunidade } \\
\text { virtual informal de } \\
\text { profissionais na área de } \\
\text { tecnologia }\end{array}$} & \multirow{4}{*}{2018} \\
\hline $\begin{array}{c}\text { Marcos do Couto Bezerra } \\
\text { Cavalcanti } \\
\end{array}$ & UFRJ & & \\
\hline Rodrigo Duarte Guedes & UFRJ & & \\
\hline Valéria Macedo & UFRJ & & \\
\hline
\end{tabular}

Fonte: Elaborado pelos autores a partir de dados extraídos dos anais do Congresso Nacional de Gestão do Conhecimento - KM BRASIL (2002-2018).

Constatamos a presença de 73 autores, todos de nacionalidade brasileira, distribuídos individualmente e em coautoria, identificando filiação a que estavam vinculados à época da publicação no evento. Averiguamos que os autores se associam a 28 instituições diferentes, dentre empresas privadas, universidades particulares e públicas. A partir do corpus coletado, registramos 15 autores vinculados à Universidade Federal de Santa Catarina, entre mestrandos, doutorandos e professores, que publicaram nas temáticas do estudo que ora realizamos.

A partir das palavras-chave dos trabalhos que citam/referenciam Polanyi, enfatizamos as mais reincidentes, ou seja, aquelas que mais aparecem nos trabalhos: gestão do conhecimento; vantagem competitiva; criação de conhecimento; compartilhamento de conhecimento; conhecimento; capital intelectual.

Observamos que os trabalhos referem a estudos que discutem aplicabilidade prática de metodologias e ferramentas direcionadas à geração e à ampliação de conhecimento no contexto das empresas. Grande parte se distribui ou se configura em algo construtivo, porquanto se observa que as discussões usam o campo teórico para respaldar e se fortalecer na direção de desenvolver a prática e a contribuição social. 
Analisando as perspectivas temáticas, visualizamos que o termo gestão do conhecimento se apresenta em destaque, presente em 21 trabalhos, o que corresponde a $70 \%$. Podemos associar isso ao fato de ser a temática central do evento e as discussões girarem em torno deste elemento, em especial no que respeita a aplicação e contribuição no âmbito organizacional.

Por vivenciarmos a era do conhecimento, autores como Nonaka e Tacheuchi (1997) e Valentim (2002) acreditam que o conhecimento tácito, após transformar-se em explícito por um processo de socialização, origina um ativo passível de ser gerido, armazenado, disseminado, sendo elemento de vantagem competitiva. Este último termo também figura no conjunto de palavras-chave e é absorvido pelas organizações, dentro do mercado consumidor oscilante, objetivando que sua aplicação potencialize e melhore o processo para futura tomada de decisão.

É comum que autores que investigam a temática da gestão do conhecimento utilizem os preceitos polanyianos para construir seus estudos, uma vez que o grande objetivo para os que trabalham de forma prática com conhecimento é tentar a conversão do tácito para o explícito, pois consideram que melhores insights, ideias e estratégias podem contribuir de forma significativa e diferenciada para a organização e se encontram na dimensão tácita do ser. Nonaka e Tacheuchi (1997), inclusive, desenvolveram um esquema para entender melhor esse processo de conversão, a chamada espiral do conhecimento, com quatro fases de processamento: socialização, externalização, combinação e internalização.

Há $20 \%$ das publicações com a temática criação de conhecimento. A teoria de criação do conhecimento organizacional situa-se no âmbito da área das Ciências Sociais e sua discussão emerge no fim do século $\mathrm{XX}$, dando uma perspectiva mais dinâmica à Ciência da Administração, que necessita de enfoques conceituais e práticos para desenvolver estratégias e alcance de vantagem competitiva com capacidade de produção e de estratégias inovadoras para manter-se rentável, na configuração da sociedade industrial.

Ainda na perspectiva do levantamento realizado no KM BRASIL, verificamos que a maioria dos autores estão inseridos no campo das Ciências 
Sociais, e compreende em sua maioria um público de pós-graduandos das áreas da Ciência da Informação, Administração, Gestão do Conhecimento e Sistemas de Informação, exceção feita somente às Engenharias.

Para Nonaka e Tacheuchi (1997), criar conhecimento organizacional é a habilidade da empresa em produzir um conhecimento, disseminá-lo na organização e aplicá-lo a produtos, serviços e sistemas, e neste limiar situa-se o poder das empresas japonesas em inovar (estudadas por eles), o que se volta ao desenvolvimento de vantagem competitiva, atinando ao processo: criação de conhecimento -> inovação contínua -> vantagem competitiva.

Murasse, Moreira e Strauhs (2014) chamam atenção para o $b a$ como espaço fomentador à criação do conhecimento no contexto de uma organização, desta forma, a geração do conhecimento nestes ambientes deve ser compreendida "[...] como processo que permite compartilhar e expandir o conhecimento dos indivíduos. Esse processo de expansão ocorre dentro de uma comunidade ou espaço - ba do conhecimento, baseado em interações humanas intencionais" (MURASSE; MOREIRA; STRAUHS, 2014, p. 3). Vale frisar o papel do gestor na criação de conhecimento, peça-chave na condução das pessoas que se encontram em momentos de ebulição de ideias, do from-to, ou, ainda, dos elementos subsidiários aos elementos distais, quando o conhecimento se forma.

Conforme Nonaka e Tacheuchi (1997), a gestão residirá sob o conhecimento explícito (estruturado, codificado), entretanto, se faz importante considerarmos os preceitos de Polanyi (1966) ao entender que na formalização do conhecimento, o tácito não pode ser desconsiderado ou excluído, pois está interiorizado. Sendo tácito, pessoal, do ser pensante, questionamos se existe realmente gestão do conhecimento ou gestão de informações (conhecimento explícito). Apenas é conhecimento quando o internalizamos (faz sentido para quem o obtém), do contrário, ou é dado ou informação:

Em Polanyi se encontra a matriz fundamental para uma compreensão do processo de construção do conhecimento, ou para epistemologia que conduza de modo decidido a dimensão pessoal. Essa pessoalidade, segundo ele, não pode ser confundida com a caricatura da ideia de subjetividade, associada com a mera 
passividade ou arbitrariedade no confronto com a realidade concreta: significa, isto sim, pessoal, e como tal, é absolutamente impossível separar nitidamente as dimensões tácita e explícita do conhecimento que reside em cada um de nós, em qualquer contexto. (SAIANI, 2004, p. 5-6).

Outra temática mais reincidente diz respeito ao compartilhamento de conhecimento, ocupando 13,33\% do total. Embora o percentual seja o menor identificado nas palavras-chave das produções selecionadas, compreende-se que o compartilhamento é estimulado pela criação e produz vantagem competitiva, portanto, as temáticas antecedentes contribuem para que se compartilhe.

Para Polanyi (1966), o verdadeiro conhecimento está alicerçado na ação individual do ser humano e, nessa direção, é preciso recuperar a ligação entre o conhecimento e suas circunstâncias criadoras para ser externalizado. Ou, conforme Saiani (2004), "no caso de Polanyi, nossas sensações são levadas a sério e a percepção sensorial é o primeiro momento da construção do conhecimento" (SAIANI, 2004, p. 6). Registra-se que se torna mais eficiente no processo de compartilhamento do conhecimento, porquanto, experienciar ações de conhecimento nos auxilia a internalizá-lo com mais eficácia, pois só interiorizando os elementos distais, nós podemos compreender o significado conjunto. Quando o tácito predomina a ponto de inviabilizar o processo de conversão para o explícito, estamos diante de um conhecimento inefável, em virtude, justamente, da dimensão tácita estar imbuída de significados impossíveis de serem expressos (GRANT, 2007).

Podemos depreender que o compartilhamento consiste em processo paralelo ao de criar conhecimento. Ao passo que, por exemplo, quando demonstramos para um grupo de aprendizes determinada técnica para produzir uma receita específica ou desenvolvemos um caderno com receitas de família para disponibilizar ao público, estamos apresentando/externalizando nossos conhecimentos para outrem. Teixeira (2008) chama atenção para os percentuais de conhecimento que ficam armazenados no cérebro em razão da forma como se transmite: "ler retém $10 \%$, ouvir, $26 \%$, ver, $30 \%$, ver e ouvir, $50 \%$, conversar com outrem, $70 \%$, fazer, $80 \%$, dizer como fazer, 90\% e, ensinar, 95\%" (COOK, $1988^{3}$ apud TEIXEIRA, 2008, p. 5). 
Em síntese, a ação de compartilhar conhecimento requer do indivíduo habilidades empíricas e cognitivas que, no âmbito organizacional, constatam-se empresas e instituições que utilizam estratégias e criam condições que possibilitam a interação entre pares, conduzindo o livre trânsito entre experiências vividas e o indivíduo que compreende e as dissemina (GARCIA; SILVA, 2015).

Empresas contratam profissionais levando mais em consideração a experiência que possuem do que sua inteligência ou seu grau de instrução. "Estudos demonstram que os gerentes adquirem dois terços de informação e conhecimento em reuniões face a face ou em conversas telefônicas. Apenas um terço provém de documentos" (TEIXEIRA, 2008, p. 2).

Tais considerações coadunam-se com os preceitos de Birkinshaw (2001) ao enquadrar três possibilidades como estratégias organizacionais para criação e ampliação de conhecimento: (1) Interação com os membros da empresa (trocas de experiências baseadas na performance do indivíduo); (2) Interação com os arquivos da empresa (documentos e materiais permeados de informação orgânica) e (3) Atualização, renovação e inovação da base de conhecimentos para além das fronteiras da empresa.

Todavia, é salutar frisar que, na concepção de Polanyi (1966), é imperioso que sempre haja uma constante articulação entre os conhecimentos tácito e explícito na composição do conhecimento, no estabelecimento do valor dele e no entendimento do seu fluxo contínuo ou não.

A palavra-chave conhecimento (de forma isolada) foi reincidente nas produções, estando em 16,66\%. As discussões caminharam, especialmente, para categorizar tácito e explícito. Dos trabalhos analisados, 34 autores utilizaram a teoria polanyiana para justificar a dicotomia entre conhecimento tácito e explícito e introduzir as discussões em torno do conhecimento organizacional utilizando outros autores.

Outrossim, 13 autores utilizaram a teoria objeto desse artigo para enquadrar o conhecimento, especialmente o tácito como vantagem competitiva organizacional. Corroboramos com o que preconiza Choo (2011, p.179) ao considerar o conhecimento como "elemento estratégico, essencial e que se 
configura como uma propriedade de vantagem competitiva e duradoura para uma organização". Ele assinala que o conhecimento constitui resultado da rede de relacionamentos que a organização mantém com clientes, fornecedores e associados no decorrer dos anos, o que lhe dá subsídios para intensificar sua produção e projeção atual e futura.

Importante, ainda, destacar que, segundo Muniz Junior, Maia e Viola (2011, p. 8), "o tema conhecimento tácito tem atraído a atenção para publicação internacional na última década e, no período de 2008-2010, o número de publicações acelerou", indicando Michael Polanyi como um dos principais estudiosos na área.

Vinte e nove autores, ou seja 41,42\% dos 70, adotaram as considerações de Polanyi (1966) com inclinação para discutir o conhecimento tácito, com foco no seu caráter pessoal e na dimensão profunda do ser, especialmente na perspectiva da frase mais conhecida do autor - "Nós sabemos mais do que conseguimos dizer" - e, a partir disso, relacionar ao que se entende por capital intelectual (palavra-chave que figura em 10\% das produções) dos sujeitos assentados na dimensão tácita do conhecimento, com potencial inovativo, “[...] socialmente construído e se funda sobre a experiência pessoal da realidade" (LEONARDI; BASTOS, 2014, p. 13).

Nas concepções erguidas, verificamos que o questionamento de Garcia e Silva (2015) estão corretos ao confrontar a literatura para afirmar que, sob os preceitos de Polanyi (1966), não há gestão sobre o conhecimento. Na verdade, verifica-se que gestores e empresas, de forma geral, utilizam metodologias e ferramentas que viabilizam e estimulam a criação e o compartilhamento de conhecimento, mas não gestão, porquanto esta, reside em outros elementos.

Quadro 3 - Estratégias de criação e ampliação de conhecimento

\begin{tabular}{|c|c|}
\hline ESTRATÉGIA & DESCRIÇÃO \\
\hline $\begin{array}{c}\text { Incutir visão de } \\
\text { futuro }\end{array}$ & $\begin{array}{c}\text { Internalização no colaborador da visão organizacional para que } \\
\text { permaneça apto às mudanças provocadas pelo ambiente externo, } \\
\text { equalizando-as com a pretensão de status futuro da empresa }\end{array}$ \\
\hline
\end{tabular}




\begin{tabular}{|c|c|c|}
\hline $\begin{array}{c}\text { Desenvolver } \\
\text { comunidades de } \\
\text { prática }\end{array}$ & $\begin{array}{c}\text { Produção de conhecimento, pela interação dos indivíduos em um } \\
\text { ambiente em que se cria, sustenta e abastece. A cooperação permeia o } \\
\text { processo, pela participação e identidade em relação à comunidade a que } \\
\text { pertence }\end{array}$ \\
\hline $\begin{array}{c}\text { Criar o contexto } \\
\text { adequado }\end{array}$ & $\begin{array}{c}\text { Criação e disseminação de conhecimento (individual ou coletivo), } \\
\text { prezando pela interação dos membros da organização em ambiente } \\
\text { propício. O conceito de ba aplica-se e é criado para que esta finalidade } \\
\text { ocorra }\end{array}$ \\
\hline $\begin{array}{c}\text { Mobilizar } \\
\text { ativistas de } \\
\text { conhecimento }\end{array}$ & $\begin{array}{c}\text { Coordenação de indivíduos que propicia a criação de conhecimento, } \\
\text { funcionando como verdadeiros catalisadores, pois, reúne pessoas com } \\
\text { habilidades ou cria contextos para ebulição de conhecimento }\end{array}$ \\
\hline $\begin{array}{c}\text { Globalizar } \\
\text { conhecimento } \\
\text { local }\end{array}$ & $\begin{array}{c}\text { Ampliação e repercussão do conhecimento que se cria em nível local } \\
\text { para outros ambientes, o que propicia o desenvolvimento de novos } \\
\text { insights e novas ideias }\end{array}$ \\
\hline $\begin{array}{c}\text { Bricolagem } \\
\text { Captação de conhecimento a partir da reunião de ideias e percepções de } \\
\text { sujeitos distintos, refletindo sobre elas a partir da criação do } \\
\text { conhecimento enquanto prática social }\end{array}$ \\
\hline $\begin{array}{c}\text { Construção de sentido em gaps ou lacunas na esfera cognitiva e a partir } \\
\text { das experiências sanar as lacunas }\end{array}$ \\
\hline
\end{tabular}

Fonte: Adaptado de Garcia e Silva (2015).

Podemos também verificar essa perspectiva nos documentos dos anais do KM BRASIL ou em Garcia e Silva (2015), ao reunir e descrever estratégias para criação e compartilhamento de conhecimento, ressaltando que, na maioria das vezes, são desempenhadas pelo entrelaçamento entre várias das aqui apresentadas e mais outras que possam também ser experienciadas.

\section{Considerações Finais}

Quanto ao cerne deste trabalho, o de averiguar as discussões em torno da teoria do conhecimento de Michael Polanyi, percebemos que embora sua teoria tenha sido elaborada há décadas, ela ainda é discutida e apresentada por parte de estudiosos do campo das Ciências Sociais Aplicadas, de forma especial da Administração, da Ciência da Informação e das Engenharias. Podemos apreender que o introito para as discussões sobre gestão, criação, transferência ou armazenamento de conhecimento partem da epistemologia polanyiana refletida nos trabalhos desse estudo.

Da análise dos anais do KM BRASIL (2002-2018), percebemos que a teoria de Polanyi se incorpora ao contexto brasileiro, embora são encontrados pouco mais de $5 \%$ do total de trabalhos nos 13 anos de evento. Quanto à filiação 
dos autores que citam Polanyi, evidencia-se a Universidade Federal de Santa Catarina com maior número de trabalhos publicados. Tal constatação pode estar associada ao fato de a instituição comportar um Programa de Pós-graduação em Engenharia e Gestão do Conhecimento, direcionando discussões para o evento temático da área.

Quanto às perspectivas, evidenciamos que a gestão do conhecimento ganha o centro das discussões dos estudos publicados no KM BRASIL com trabalhos tanto de caráter bibliográfico como de natureza aplicada. Entende-se que a utilização do termo gestão se torna equivocada quando associada ao elemento conhecimento. Como assinalam Garcia e Silva (2015) que isso se constitui em dificuldade teórica e prática de aceitação do termo, porquanto, estão condizentes que, com efeito, são processos e métodos executados com intuito de criar e socializar conhecimento.

$\mathrm{O}$ artigo cumpriu caracterizar a produção dos anais do KM Brasil e discutir as temáticas mais reincidentes nas palavras-chave extraídas dos trabalhos levantados, contudo a temática é ampla e abarca uma série de outros contextos e temas, dentre eles: cultura organizacional, sistemas de informação, inteligência, desenvolvimento humano, sustentabilidade, Tecnologias da Informação e Comunicação (TIC), dentre outros.

Por fim, apresenta contribuição especial para as discussões de gestão do conhecimento no âmbito da Ciência da Informação brasileira, partindo dos anais do KM BRASIL sob o prisma dos preceitos polanyianos. Outrossim, consideramos que deva haver maiores estudos na perspectiva do autor objeto desse trabalho, especialmente no âmbito da Ciência da Informação, por entendermos que estudos de criação e ampliação do conhecimento podem se adequar a esta ciência, como designador para o desenvolvimento do processo.

\section{Referências}

ALBAGLI, S. Informação, conhecimento e desenvolvimento. In: VI Encontro Nacional de Pesquisa em Ciência da Informação, 2005, Florianópolis. Anais [...] Florianópolis: UFSC, 2005.

BIRKINSHAW, B. Why is knowledge management so difficult? Business strategy review, West Sussex, v. 12, n.1, p. 11-18, 2001. 
CARDOSO, L.; CARDOSO, P. Para uma revisão da teoria do conhecimento de Michael Polanyi. Revista Portuguesa de Pedagogia, Coimbra, v. 41, n. 1, p. 41-54, 2007.

CHOO, C. W. A organização do conhecimento. 3 ed. São Paulo: Senac, 2011.

CRUZ, T. Sistemas, organizações \& métodos: estudo das novas tecnologias de informação. 3. ed. São Paulo, Atlas, 2002.

GARCIA, J. C. R.; SILVA, E. M. Nuanças e estratégias que circundam o conhecimento tácito. Navus - Revista de Gestão e Tecnologia, [s. 1], v. 5, n. 3, p. 6-21, 2015.

GRANT, K. A. Tacit Knowledge revisited: we can still learn from Polanyi. The Eletronic Journal of Knowledge Management, [s. 1], v.5, n.2, p. 173-180, 2007.

LEONARDI, J.; BASTOS, R. C. Bases epistemológicas da teoria de criação de conhecimento organizacional. Perspectivas em Gestão \& Conhecimento, [s. 1], v. 4, n. 2, p. 3-18, 2014.

MUNIZ JR, J.; MAIA, F. G. M.; VIOLA, G. Os principais trabalhos na teoria do conhecimento tácito: pesquisa bibliométrica 2000-2011. XIV Simpósio De Administração da Produção, Logística e Operações Internacionais. Anais [...] São Paulo, 2011.

MURASSE, C. M.; MOREIRA, P. T. A.; STRAUHS, F. R. Teoria e prática das condições habilitadoras do ba na criação de conhecimento. In: CONGRESSO NACIONAL DE GESTÃO DO CONHECIMENTO, KM BRASIL, 11, 2014, São Paulo, SP. Anais [...] São Paulo: KM BRASIL, 2014.

NONAKA, I. A Dynamic Theory of Organizational Knowledge Creation. Organization Science, [s. 1], v. 5, n. 1, p. 14-37, 1994.

NONAKA, I.; TAKEUCHI, H. Criação de conhecimento na empresa: como as empresas japonesas geram a dinâmica da inovação. Rio de Janeiro, Campus, 1997.

PEREIRA A. L.; BACHION, M. M. Atualidades em revisão sistemática de literatura, critérios de força e grau de recomendação de evidência. Rev Gaúcha Enferm, Porto Alegre, 2006.

POLANYI, M. The tacit dimension. London: Routdedge \& Kegan Paul, 1966.

ROCHA-NETO, I. Gestão do conhecimento e complexidade. Revista de Gestão e Projetos - GeP, São Paulo, v. 3, n. 1, p 94-126, jan./jun. 2012. 
SAIANI, C. O valor do conhecimento tácito: a epistemologia de Michael Polanyi na escola. São Paulo: Escrituras Editora, 2004.

SAMPAIO, R. F. MANCINI, M. C. Estudos de revisão sistemática: um guia para síntese criteriosa da evidência científica. Revista brasileira de fisioterapia, v. 11, n. 1, p. 83-89, 2007.

SANTA'ANNA, J. O arquivista como gestor de recursos informacionais: uma reflexão acerca dos novos modelos de gestão. Ágora, Florianópolis, v.25, n.51, p.77-100, jul./dez. 2015.

SCHARTINGER, D.; MAIA, F. G. M.; VIOLA, G. Knowledge interactions between universities and industry in Austria: sectoral patterns and determinants. Research Policy, Amsterdam, v. 31, n. 3, p. 303-328, 2002.

SCOTT, W. T; MOLESKI M. Michael Polanyi: scientist and philosopher. Oxford: Oxford University Press, 2005.

TEIXEIRA, M. R. F. Gestão do conhecimento e memória organizacional: Compartilhando conhecimento em ambientes universitários. In: Congresso Nacional de Gestão do Conhecimento, KM BRASIL, 6, 2008, São Paulo, SP. Anais [...] São Paulo: KM BRASIL, 2008.

VALENTIM, M. L. P. Inteligência competitiva em organizações: dado, informação e conhecimento. DataGramaZero, Rio de Janeiro, v. 3, n. 4, p. 1$13,2002$.

\title{
Repercussion of Michael Polanyi's Tacit Knowledge Theory: Km Brasil 2002-2018 proceedings
}

\begin{abstract}
Discussions about the epistemology of knowledge are very old and cover areas from Health Sciences to Applied Social Sciences. In it we have an important figure: Michael Polanyi, proposing a harmonious perspective for the creation of knowledge, breaking the ideal of absolute objectivity inherited from the Scientific Revolution of the 18th century. The quali-quanti research uses data published in the documents published in the proceedings of the National Congress of Knowledge Management - KM BRASIL (2002-2018) that mention Polanyi's concept of tacit knowledge in order to identify how his ideas are referred, the senses used and their development. In this direction, from KM BRASIL, we show authors, affiliations, date of publication, including possibilities to interpret Polanyi's ideas. We found that the theory is approached conceptually in the Brazilian context, corresponding to just over 5\% of the total works published in the 13 years of the event. Although the theme of knowledge management occupies the center of the event's discussions, only this percentage
\end{abstract}


cites the studies of Michael Polanyi. Indeed, the selected authors claim to be anchored in Polanyi's precepts to explain the epistemology of knowledge and its categorization. Subsequently, the authors insert the notion of management and the distinction between the tacit and the explicit from Nonaka and Takeuchi (1997). We apprehend that the introduction to the discussions on management, creation, transfer or storage of knowledge has always started from Polanyian epistemology, although not always in a reliable way.

Keywords: Tacit knowledge. Michael Polanyi. KM Brazil.

Recebido: $18 / 06 / 2020$

Aceito: 26/03/2021

\section{Declaração de autoria}

Concepção e elaboração do estudo: Josemar Elias da Silva Junior, Joana Coeli Ribeiro Garcia

Coleta de dados: Josemar Elias da Silva Junior, Joana Coeli Ribeiro Garcia

Análise e discussão de dados: Josemar Elias da Silva Junior, Joana Coeli Ribeiro Garcia

Redação e revisão do manuscrito: Josemar Elias da Silva Junior, Joana Coeli Ribeiro Garcia

\section{Como citar}

SILVA JUNIOR, Josemar Elias da; GARCIA, Joana Coeli Ribeiro.

Repercutindo a teoria do conhecimento tácito de Michael Polanyi nos anais da Km Brasil 2002 - 2018. Em Questão, Porto Alegre, v. 27, n. 3, p. 306-327, 2021. Doi: http://dx.doi.org/10.19132/1808-5245273.306-327

${ }^{1}$ Conforme Rocha-Neto (2012), a esteira histórica da gestão do conhecimento é compreendida a partir de três gerações, sendo primeira compreendida no período anterior a 1995, em que tínhamos o conhecimento enquanto fluxo informacional auxiliador da tomada de decisão e a apresentação de novas tecnologias da informação e comunicação, que cumpriam com o mister único de auxiliar no mapeamento dos conhecimentos existentes.

2 Interação, criação, geração, disseminação, difusão, transferência, compartilhamento, fluxo e transbordamento.

${ }^{3}$ COOK, S. Culture and Organizational Learning. Journal of Management Inquiry, New York, v.2, n.4, p.373-390, 1998. Apud Teixeira (2008). 